\title{
The Complications of Radical Prostatectomy in the Atlas Shepherd Dog: Clinical and Echographic Follow Up
}

Ahmed Boucif ${ }^{*}$, Khadidja Madani, Aboud Boulkaboul and Khaled Slimani

Laboratory of farm animal reproduction, Institute of veterinary sciences, University Ibn Khaldoun, BP 78, Tiaret-14000, Algeria.

*Corresponding author: Ahmed Boucif, Laboratory of farm animal reproduction, Institute of veterinary sciences, University Ibn Khaldoun, BP 78, Tiaret-14000, Algeria, Tel: +213 65234059; E-mail: mahmed7014@gmail.com

Rec date: Aug 30, 2015; Acc date: Nov 13, 2015; Pub date: Nov 16, 2015

Copyright: ( 2015 Boucif A, et al. This is an open-access article distributed under the terms of the Creative Commons Attribution License, which permits unrestricted use, distribution, and reproduction in any medium, provided the original author and source are credited.

\begin{abstract}
The aim of this study is to raising the possible difficulties and the complications met in intra and post-operatively during a radical prostatectomy $(R P)$. Four $(n=4)$ healthy Atlas Shepherd Dog, of 2 years old underwent a RP on the level of the canine clinical pathology of Tiaret veterinary science Institute (Algeria).

A clinical and echographic follow-up post-operative revealed the presence of a light urinary incontinence, solved in the short run for two dogs. Whereas it is persistent and complicated in cystitis and a leakage of the urine at the anastomosis site in the two other dogs. A treatment containing antibiotics systemically and locally associated with a disinfection of the wounds was set up.

Following a hospitalization two dogs were restored completely, whereas the two others had inevitable complications been dependant on the urinary system. For a good management of the complications related to total prostatectomy, a rigorous clinical follow-up, associated with an ultrasonographic examination prove to be essential.
\end{abstract}

Keywords: Dog; Shepherd Atlas; Prostatectomy; Echography; Urinary incontinence; Cystitis; Leak of anastomosis

\section{Introduction}

The prostate is the only secondary sexual gland of the male dog. It is not a vital organ but it is frequently the seat of varied affections, being able to have sometimes serious clinical effects [1]. Certain affections are difficult to treat and often require a surgical intervention from where many techniques were described but much are associated with complication rates and recurrence high. However, RP is the only technique which allows the complete prostatic tissue excision, which makes it possible to eliminate the problem from its source [2]. This technique remains an indication in the case of prostatic tumors which have not metastasized although no study shows significant rise of the duration of survival after RP in the dog reached of a prostatic carcinoma. It can also be regarded as a procedure of last recourse in the dogs with a severe traumatism of the prostate or an important repetition of the formation of abscess or cysts $[3,4]$.

\section{Materials and Methods}

Four $(n=4)$ male dogs of local race (Shepherd Atlas), of 3 years old on average (From 2 to 5 years) with an average weight of $18 \mathrm{~kg}$, were used in this study (Table 1).

After having dewormed and vaccinated the dogs, a clinical review of the general state, in particular the appreciation of the great functions was realized before proceeding to the operative intervention.

The examination of the genito-urinary tract and more particularly the appreciation of the state of the prostate by echography and palpation transrectal in the four dogs did not reveal of problem (Figure 1).

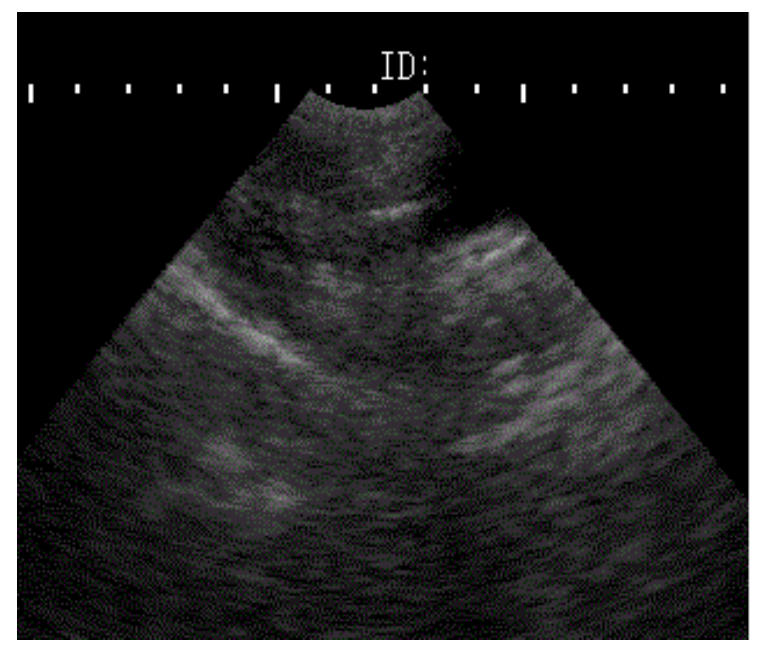

Figure 1: Ante-operative longitudinal echographic view, normal state of the prostate.

\section{Surgical steps}

A urethral probe (Foley catheter) is installation by retrograde way since the beginning of the intervention until the ten postoperative days in order to allow a better localization of the urethra during the surgery and to eliminate the urine (Figure 2). 
Citation: Boucif A, Madani K, Boulkaboul A, Slimani K (2015) The Complications of Radical Prostatectomy in the Atlas Shepherd Dog: Clinical and Echographic Follow Up. J Veterinar Sci Technol 6: 271. doi:10.4172/2157-7579.1000271

Page 2 of 6

After a pre-anesthetic preparation indicated in total prostatectomy, the procedure proceeded under general anesthesia according to common operation [2]. The prostate is approached by abdominal way, and then insulated by dissecting the ventral prostatic perished fat. The prostate is turned over to dissect its very innerved and irrigated dorsal face. Always with its dorsal face, the vasa deferens is then located, bound and cut (Figure 3).

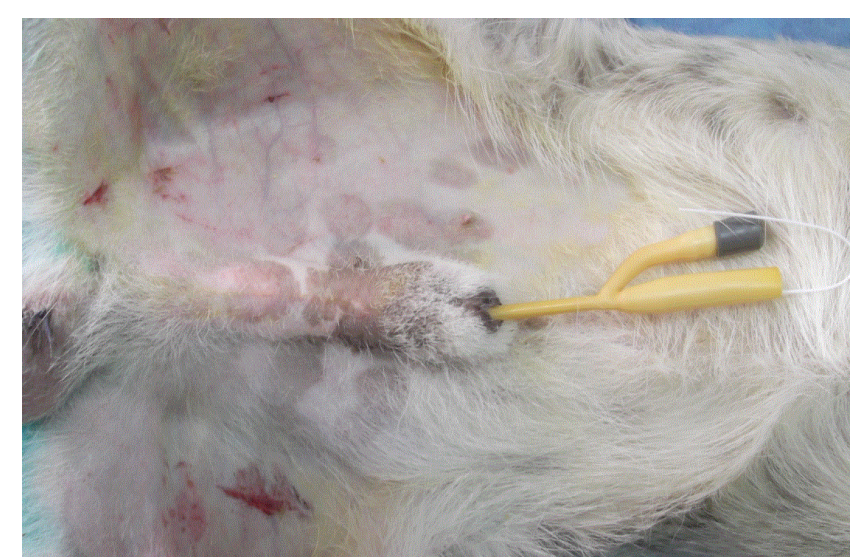

Figure 2: Ante-operative view, installation of the urinary catheter.

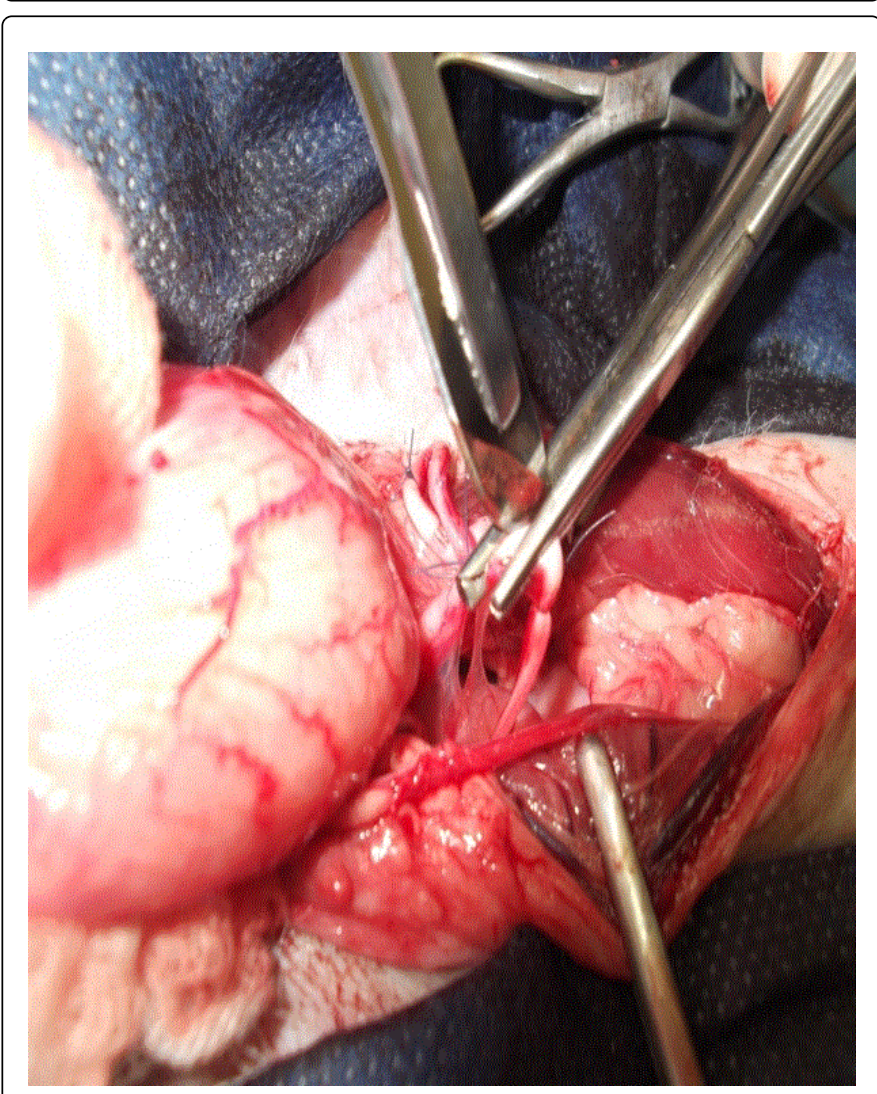

Figure 3: Intra-operative view, section of the vas deferens.

Dissection foam is carried out between the cranial part of the prostate and the vesical neck, then between the caudal part of the membranous gland and urethra. The prostate as well as the prostatic urethra is then withdrawn (Figure 4). The urethra is braided with the vesical collar in separate simple points using an absorbable monofilament (AM) 0/4 to obtain a tight closing of the urethra.

The abdominal cavity is typically closed with a simple muscle running suture using an $\mathrm{AM} 0 / 3$, then a subcutaneous running suture with a AM $0 / 2$ and finally a simple running suture skin with a no absorbable monofilament 0/2 (Figure 5).

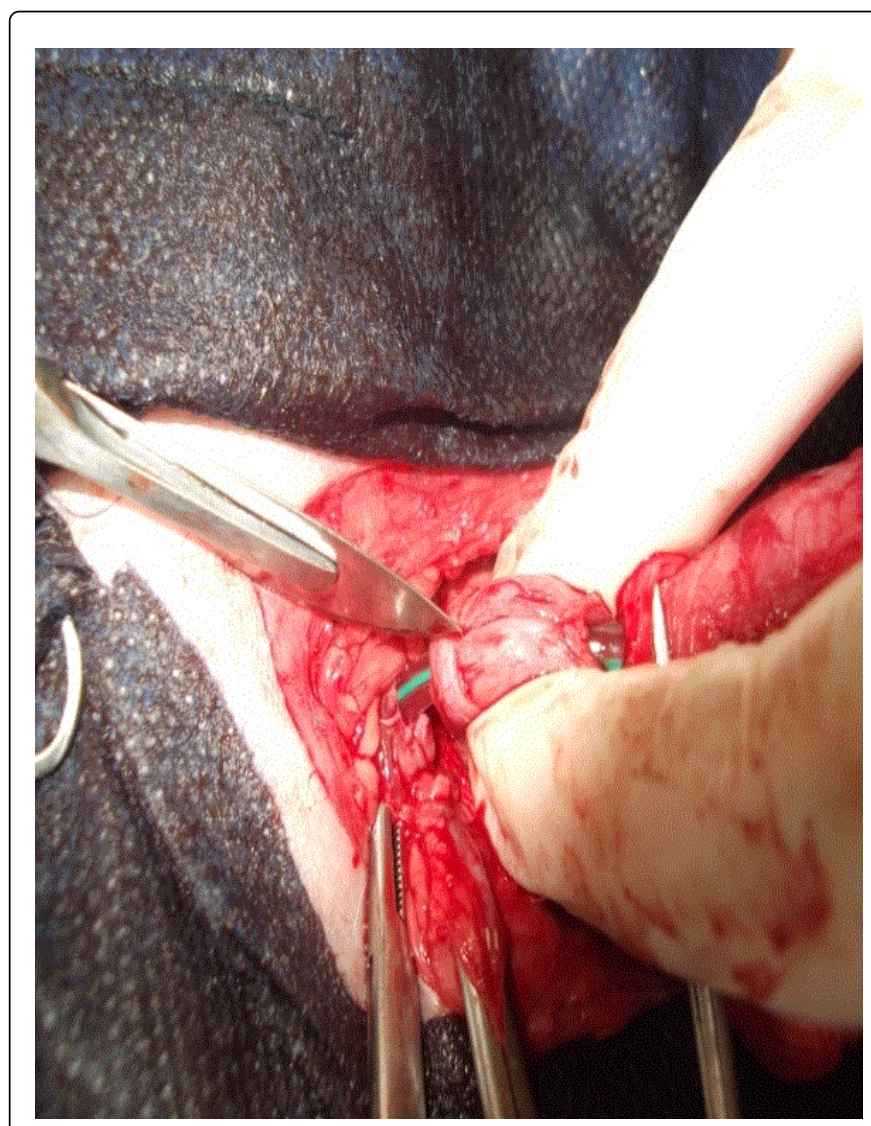

Figure 4: Intra-operative view, elimination of the prostate and the prostatic urethra.

\section{Postoperative treatment}

Regular clinical exams are carried out several times per day for the four dogs. The postoperative follow-up consists in supervising the vital functions of the dogs, in particular the production of urine and carrying out an effective analgesia.

The urethral probe was withdrawn 10 days after the operation. A fluid therapy initiated into preoperative is continued to the complete alarm clock of the animal.

A sonography examination was carried out for the whole of the dogs operated in order to detect and follow as soon as possible the evolution of the postoperative complications. Considering the presence of certain postoperative complications, it was decided to carry out hematologic assessments.

The postoperative follow-up was variable and individual according to each case until the re-establishment or death of the animal. 
Citation: Boucif A, Madani K, Boulkaboul A, Slimani K (2015) The Complications of Radical Prostatectomy in the Atlas Shepherd Dog: Clinical and Echographic Follow Up. J Veterinar Sci Technol 6: 271. doi:10.4172/2157-7579.1000271

Page 3 of 6

\section{Results}

Operational time proceeded in the principles of the traumatic and aseptic surgery with a quite neat hemostasis.

All the surgeries proceeded in 222 minutes average time between 152 to 300 minutes since the first incision until the last joining without major complications (hemorrhages, urethral lesions).

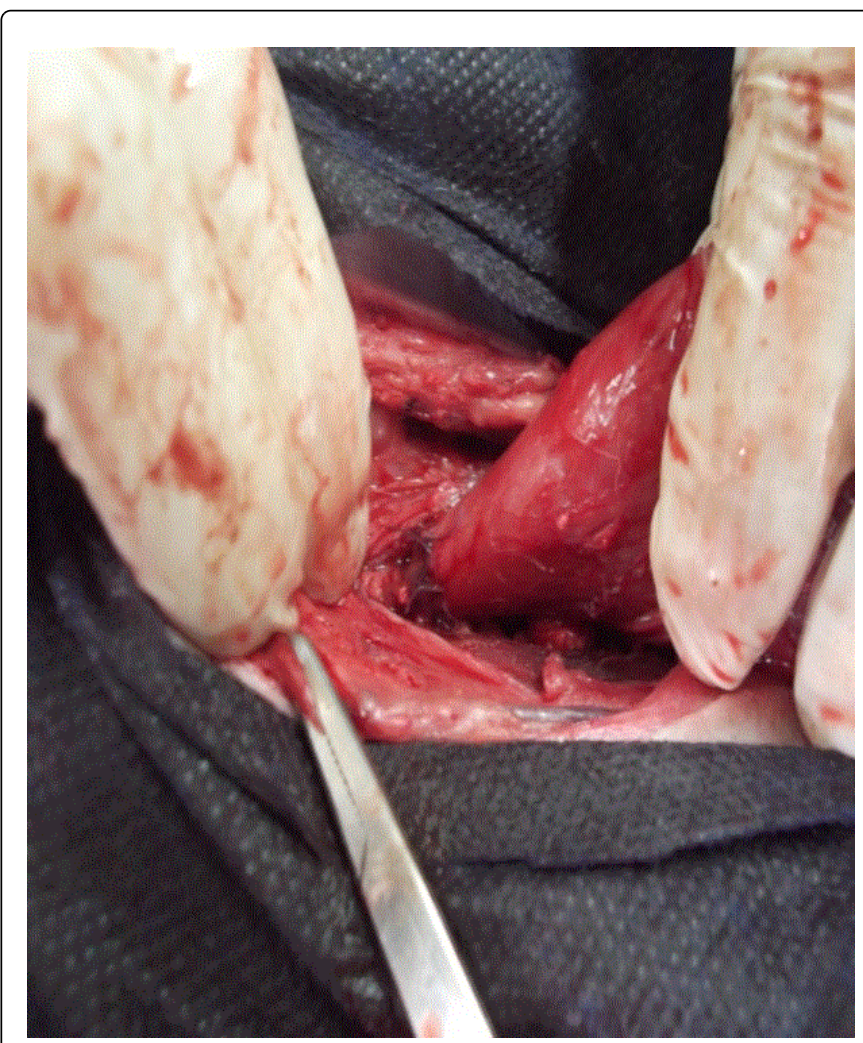

Figure 5: Intra-operative view, anastomosis of the bladder orifice with the post prostatic urethra.

The recovery was more or less long where the beginning was one hour at one hour and 45 minutes of the end of the operation. But of the difficulties were met during the operation on two occasions. At the time of the release of the prostate of its dorsal face and at the time of anastomosis of the collar of the bladder and urethra.

In addition to urinary incontinence, all the operated dogs expressed hematuria which lasted from 5 to 7 days and the tenesmus with difficulty of bowel movement during the first postoperative week.

The results of hematology showed an increase in the rate of the lymphocytes (higher than 50\%) and monocytes (superior with 10\%) during the week which followed the operation in all the operated dogs. For this purpose, a treatment containing antibiotics systemically, associated with a disinfection of the operative site using disinfectants and the antimicrobic pomades were applied.

After a 15 days hospitalization, two dogs (cases 1 and 2) start to be restored clinically by the reduction of urinary incontinence and the hematuria. The sonographic examination carried out at 60 days postoperative revealed a good healing of the urethral conduit with persistence of the hypertrophy of the vesical neck (Figure 6).
For the two other dogs (cases 3 and 4), the postoperative follow-up which lasted 8 and 35 days respectively for dogs 3 and 4 revealed a progressive degradation of their general state. Case 3 had distension to the level of the abdomen from where a yellow liquid of color pinkish was collected after an abdominal puncture; probably tear on the level of the urinary system signs.

The sonographic examination revealed the presence of the anechoic black zones in the abdomen with liquid infiltration, sign of a leakage of urethral at the anastomosis site (Figure 7).

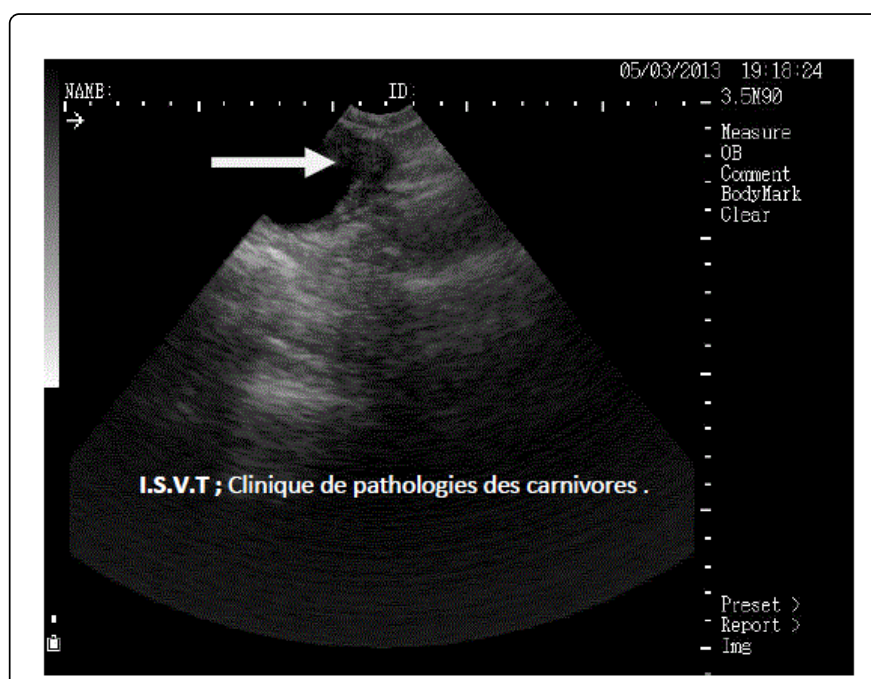

Figure 6: Post-operative longitudinal echographic view showing hypertrophy of the vesical wall (arrow).

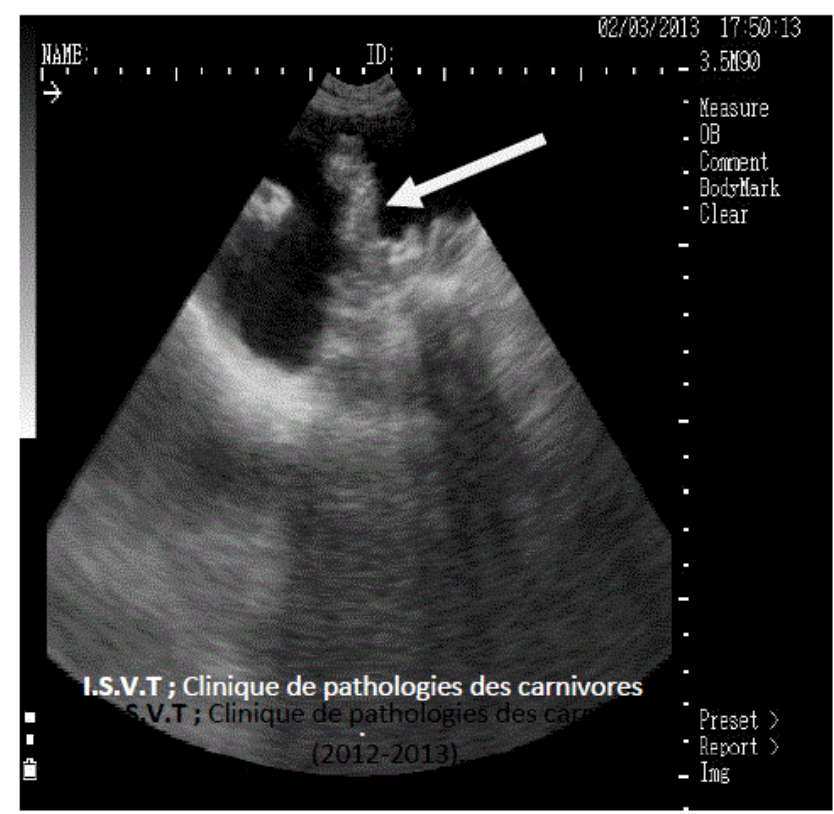

Figure 7: Post-operative longitudinal echographic view showing an anechoic zone and the presence of liquid infiltration (arrow). 
Citation: Boucif A, Madani K, Boulkaboul A, Slimani K (2015) The Complications of Radical Prostatectomy in the Atlas Shepherd Dog: Clinical and Echographic Follow Up. J Veterinar Sci Technol 6: 271. doi:10.4172/2157-7579.1000271

Page 4 of 6

Following these examinations, one decided to pass to the emergency laparotomy in order to repair the vesical wall. After the opening one found the presence of urine on the level of the abdomen (Figure 8).

However, case 4 had a persistent urinary incontinence associated with a pyuria. The sonographic examination revealed an increase thickness of the vesical wall and its echogenicity (Figure 9). This dog was put under antibiotic therapy systemically during ten days, associated with a glucose transfusion during two days. This therapeutic protocol has leads to the beginning with a re-establishment with a normal consistency of the urines, but three days afterwards, we have observed the pyuria with relapse of the animal leading to its death 35 days after the operation. A postmortem examination was carried out immediately showing characteristic lesions of cystitis (Figure 10).

After the appreciation of the degree of the lesions installed, it was decided to euthanize the two dogs (cases 3 and 4) after 35 postoperative days (Table 1).

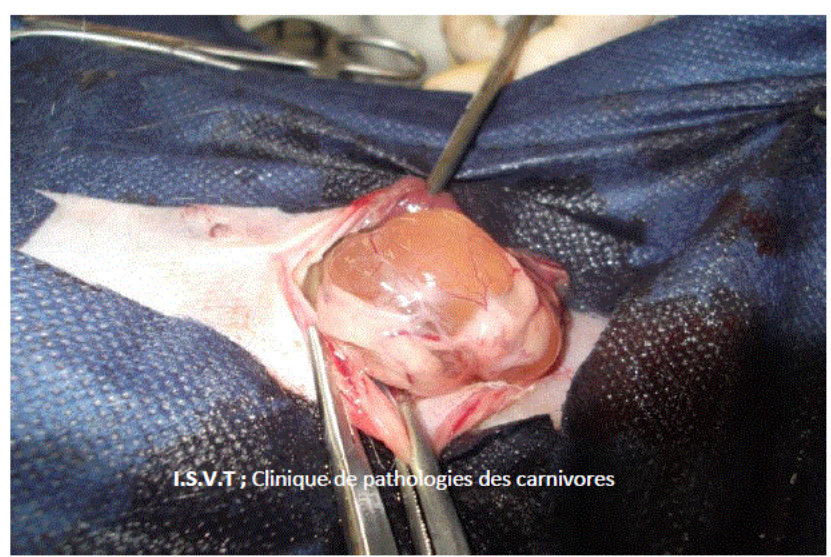

Figure 8: Post-operative view, presence of urine in the abdomen.

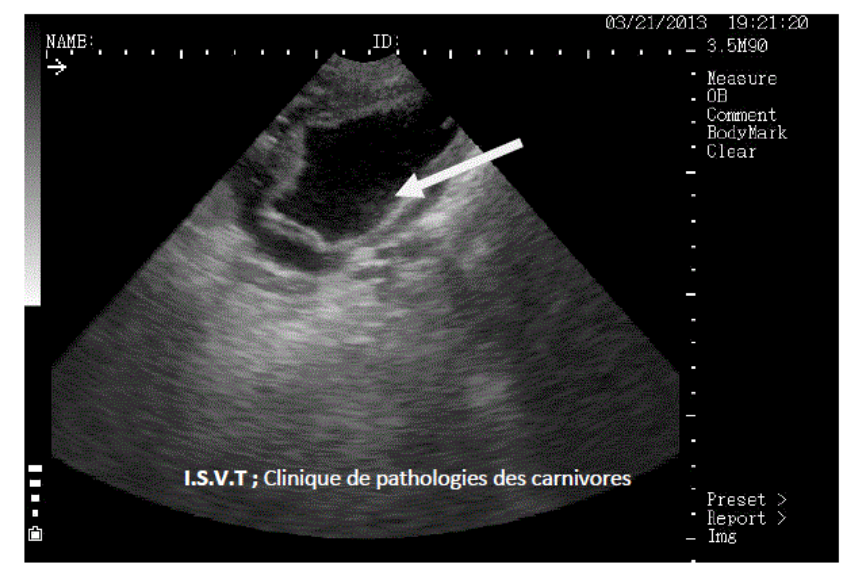

Figure 9: Post-operative longitudinal echographic view, increase thickness and echogenicity of the vesical wall (arrow).

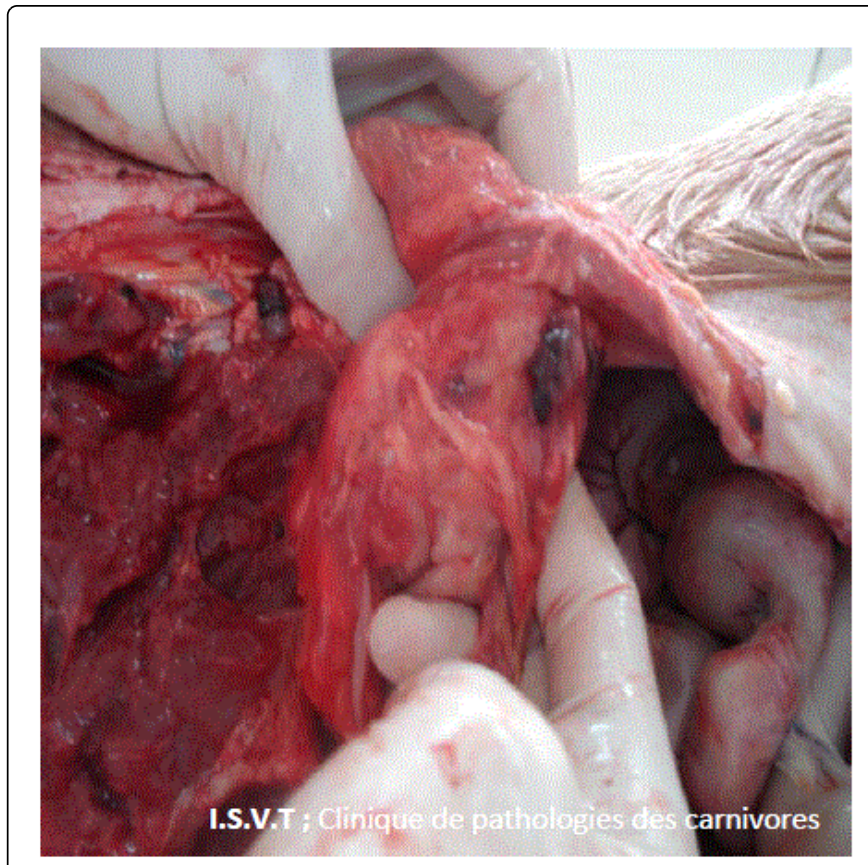

Figure 10: Post-operative view, congestion of the bladder wall.

\begin{tabular}{|c|c|c|c|c|c|c|}
\hline $\begin{array}{l}\text { Cas } \\
\text { e } \\
\text { no. }\end{array}$ & Age & $\begin{array}{l}\text { Weig } \\
\text { ht }\end{array}$ & $\begin{array}{l}\text { Duration } \\
\text { intervention (days }\end{array}$ & of & $\begin{array}{l}\text { Survival time } \\
\text { after surgery } \\
\text { (days) }\end{array}$ & $\begin{array}{l}\text { Reason for } \\
\text { euthanasia }\end{array}$ \\
\hline 1 & $\begin{array}{l}2 \\
\text { years }\end{array}$ & $16 \mathrm{Kg}$ & $\begin{array}{l}3 \text { hours and } \\
\text { minutes }\end{array}$ & 47 & 15 & Recovery \\
\hline 2 & $\begin{array}{l}2 \\
\text { years }\end{array}$ & $20 \mathrm{Kg}$ & $\begin{array}{l}3 \text { hours and } \\
\text { minutes }\end{array}$ & 30 & 15 & Recovery \\
\hline 3 & $\begin{array}{l}5 \\
\text { years }\end{array}$ & $20 \mathrm{Kg}$ & 5 hours & & 8 & $\begin{array}{l}\text { Uro- } \\
\text { peritoneum }\end{array}$ \\
\hline 4 & $\begin{array}{l}3 \\
\text { years }\end{array}$ & $18 \mathrm{Kg}$ & $\begin{array}{l}2 \text { hours and } \\
\text { minutes }\end{array}$ & 32 & 35 & Cystitis \\
\hline
\end{tabular}

Table 1: General information on the operated dogs $(n=4)$.

\section{Discussion}

For the realization of the anesthetic protocol, the general state of the animal, results of the preoperative Blood exams and the anesthetic risk as well as the duration of surgical operation were taken into account $[3,5]$. What enabled us to operate without complications nor operational pain in per.

According to the authors, the RP is a technically difficult surgery and of long life, less supported by the dogs by often involving serious postoperative complications [6], what was also noted in our study.

Basinger et al. [2] also brought back the two moments to which, we encountered the difficulties during the operation. At the time of the release of the prostate of its dorsal face which is much irrigated and much vascularized and at the time of anastomosis of the collar of the bladder and the urethra where handling was to be meticulous while avoiding important spaces between the stitches. They are the moments when it is essential to preserve to the maximum the dorsal elements of 
the prostate because any lesion is likely to involve a urinary incontinence.

Total prostatectomy is a technique which comprises great risks of postoperative complications in particular urinary incontinence $[2,3,6]$. In our study, complications were also met, represented by cases of urinary incontinence, leakage of urethral at the anastomosis site and cystitis. Urinary incontinence was reported in 33\% to $100 \%$ of all the cases treated by total prostatectomy [7]. But according to Basinger et al. [2], this complication appears in 85 to $100 \%$ of the cases of RP. In our study, two dogs (cases 1 and 2) had a light urinary incontinence which was solved in the 15 days following the operation. Similar cases were reported in work of Basinger et al. $[2,8]$, showing that the various urodynamic studies made it possible to note that the RP on healthy prostate causes only light short-term complications, in particular a light and momentary incontinence which disappeared quickly.

On the other hand, total prostatectomy in the suffering dogs of affections prostate sufferers is more likely to cause urinary incontinence, which suggests that the disease primary prostate sufferer rather than the operative procedure can be responsible for this complication $[7,9]$.

For this purpose, the dogs must be followed well into postoperative to check incontinence and the other complications. Thus, to minimize the later nerve injuries with urinary incontinence, cauterization with the dorsal face of the prostate should be maintained with a minimum [3].

Contrary to human, the RP is not an option for the treatment of prostatic tumors in the dogs because of the high incidence of postoperative incontinence [2]. It is not thus curative but only palliative.

For these reasons, the treatment modalities of prostatic tumors in the dogs need to optimize the removal of tissue neoplastic without compromising the function of the urethral sphincter, which is ordered by the nerve hypogastric lying dorso side of the prostate and the vesical neck [10]. Nevertheless, the risks related to the RP are thus not to neglect and this surgical option remains held for the severe prostatic traumatisms and the tumors which have not metastasized.

The absence of postoperative incontinence was announced in similar results reported in other techniques of dissection and in particular partial prostatectomy. This surgery allows the ablation of prostatic segments while preserving the integrity of the urethra and limits thus the risks of incontinence [11]. It also makes it possible to simplify the hemostasis and to carry out a more precise resection of prostatic tissue.

It was also reported that it has less of risk of urinary incontinence in the normal dogs compared to the dogs reached of a prostate disease, whose postoperative incidence was similar to the frequency after RP $[2,12]$. Other complications were described after total prostatectomy, as necrosis of the bladder orifice and the leak of anastomosis.

In the two other dogs examined in our study (cases 3 and 4 ), the deterioration of their general state led to serious complications, represented by cases of a leak at the anastomosis site and cystitis. These leakages occurred on the level of anastomosis involved an uroperitoneum. It is for these reason handlings were to be meticulous while avoiding important spaces between the stitches to prevent any infiltration of the urines in the peritoneal cavity. Leakage at the anastomosis site observed in the dog No. 3 is due to an escapement of sutures caused by movement of the awakening animal and sudden withdrawal of the urinary catheter.

It was reported that the leakage of the urine might be also secondary to wound dehiscence and improper suturing [8].

According to Fossum et al. [13], approximately $20 \%$ of the cases of reduction in urethral tonicity answered favorably the treatment by alpha-sympathomimetic.

The majority of the authors recommend the maintenance of the urethral probe up to 10 days after the surgical intervention in order to allow to ensure a decompression of the bladder, to reduce the tensions on the site of anastomosis, to minimize the formation of a urethral constriction and by consequence to prevent a delay with the healing $[2,14]$.

Then, it was reported that infections of the urinary tract and in particular of the cases of cystitis are present in 30 at 33\% of the cases of prostatectomy from where an antibiotic therapy of at least 6 weeks is recommended [6]. Nevertheless, the treatment of cystitis in our case does not have leads because of the anorexia and the persistence of the infection following bad an antibiotic therapy or to new resistances [2]. While according to other authors, one should not leave the urinary catheter more than three days before changing it in order to avoid the colonization of the forming urinary system by bacteria of the bio films which can involve chronic infections difficult to treat $[1,15]$. The complications from the infection and leakage of the urine might have been prevented if a pedicled omentum had been positioned around the anastomosis site [12].

It is thus recommended to carry out a clinical and echographic control animal between 1 to 6 months and at one year after the intervention for better following the re-establishment of the dogs $[3,4]$.

Although total prostatectomy does not present any recurrence, it remains a very difficult technique which requires well an antibiotic therapy and monitoring of the animal.

\section{Conclusions}

Considering the topography of the prostate as well as the various difficulties and the complications met in per and postoperative, the technique of the RP remains always difficult to realize. Good an antibiotic therapy and monitoring of the animal after the operation are essential for managing this critical period well and minimizing the possible damage. Of point of considering diagnosis, echography reveals the examination of imagery of choice to explore the bladder in order to determine its echographic aspect and to be able to diagnose its state. Nevertheless, the complications met in our study require to be supplemented by other studies relating to a higher number of animals in comparison with dogs reached of prostatic problems.

\section{References}

1. Rawlings CA (1998) Surgery of the prostate. In: Bojrab MJ, Ellison GW, Slocum B (Eds.) Current techniques in small animal surgery. Baltimore, Williams \& Wilkins Company pp: 479-484.

2. Basinger RR, Robinette CL, Spaulding KA (2003) Textbook of small animal surgery. Philadelphia Saunders 2: 1542-1557.

3. Freitag T, Jerram RM, Walker AM, Warman CG (2007) Surgical management of common canine prostatic conditions. Compend Contin Educ Vet 29: 656-658, 660, 662-3 passim.

4. Harari J, Dupuis J (1995) Surgical treatments for prostatic diseases in dogs. Semin Vet Med Surg (Small Anim) 10: 43-47. 
Citation: Boucif A, Madani K, Boulkaboul A, Slimani K (2015) The Complications of Radical Prostatectomy in the Atlas Shepherd Dog: Clinical and Echographic Follow Up. J Veterinar Sci Technol 6: 271. doi:10.4172/2157-7579.1000271

Page 6 of 6

5. Dupuy-dauby L, Dupre G, Bouvy B (1996) Surgical cases of prostate disease treatment in dogs: a retrospective study. Prat medchir Anim Cie 31: 515-524.

6. Hedlund CS (2007) Surgery of the male reproductive tract. In: Fossum TW, Hedlund CS, Johnson AL (Eds) Small animal surgery, St Louis, Mosby Elsevier pp: 747-759.

7. Goldsmid SE, Bellenger CR (1991) Urinary incontinence after prostatectomy in dogs. Vet Surg 20: 253-256.

8. Basinger RR, Rawlings CA, Barsanti JA, Oliver JE Jr, Crowell WA (1987) Urodynamic alterations after prostatectomy in dogs without clinical prostatic disease. Vet Surg 16: 405-410.

9. Basinger RR, Rawlings CA, Barsanti JA, col (1989) Urodynamic alterations associated with clinical prostatic diseases and prostatic surgery in 23 dogs. J Amer Hosp Assn 25: 385-392.

10. Krawiec DR, Heflin D (1992) Study of prostatic disease in dogs: 177 cases (1981-1986). J Am Vet Med Assoc 200: 1119-1122.
11. Van Nimwegen SA, L'Eplattenier HF, Rem AI, van der Lugt JJ, Kirpensteijn J (2009) Nd:YAG surgical laser effects in canine prostate tissue: temperature and damage distribution. Phys Med Biol 54: 29-44.

12. L'Eplattenier HF, van Nimwegen SA, van Sluijs FJ, Kirpensteijn J (2006) Partial prostatectomy using Nd:YAG laser for management of canine prostate carcinoma. Vet Surg 35: 406-411.

13. Fossum TW, Col ( 2007) Surgery of the Reproductive and Genital Systems In: Small Animal Surgery (3rdedn) Elsevier, St Louis 27: 747-759

14. Cooley AJ, Waldron DR, Smith MM, Saunders GK, Troy GC, et al. (1999) The effects of indwelling transurethral catheterization and tube cystostomy on urethral anastomoses in dogs. J Am Anim Hosp Assoc 35: 341-347.

15. White RA (2000) Prostatic surgery in the dog. Clin Tech Small Anim Pract 15: 46-51. 